\title{
A high resolution map of French soil organic carbon
}

\author{
Jeroen Meersmans • Manuel Pascal Martin • \\ Eva Lacarce • Sarah De Baets • Claudy Jolivet • \\ Line Boulonne • Sébastien Lehmann • \\ Nicolas Philippe Anthony Saby • Antonio Bispo • \\ Dominique Arrouays
}

Accepted: 20 February 2012 /Published online: 23 March 2012

(C) INRA and Springer-Verlag, France 2012
Keywords Land use $\cdot$ Manure $\cdot$ SOC $\cdot$ Rock fragment content $\cdot$ Climate $\cdot$ Soil texture $\cdot$ Spatial $\cdot$ National $\cdot$ AIC $\cdot$ AICc

$\begin{array}{ll}\text { Abbreviation list } \\ \text { ADEME } & \begin{array}{l}\text { French Environment and Energy Management } \\ \text { Agency }\end{array} \\ \text { AGRESTE } & \begin{array}{l}\text { French Ministry of Agriculture Food and } \\ \text { Fishery }\end{array} \\ \text { AIC } & \text { Akaike information criterion } \\ \text { AICc } & \text { Corrected Akaike information criterion } \\ \text { BIC } & \text { Bayesian information criterion } \\ \text { CEC } & \text { Commission of the European Communities } \\ \text { dg } & \text { geometric mean particle size } \\ \text { EEA } & \text { European Environment Agency } \\ \text { FAO } & \text { Food and Agriculture Organization of the } \\ & \text { United Nations } \\ \text { FYM } & \text { Farm yard manure } \\ \text { GEFSOC } & \text { Global Environment Facility Soil Organic } \\ & \text { Carbon } \\ \text { GIS } & \text { Geographical Information System } \\ \text { Gt C } & \text { Giga ton carbon } \\ \text { INRA } & \text { French National Institute for Agricultural } \\ & \text { Research } \\ \text { Pg C } & \text { Peta gram carbon } \\ \text { RMSE } & \text { Root mean square error } \\ \text { RMQS } & \text { French National Soil Survey (Réseau de } \\ & \text { Mesures de la Qualité des Sols) } \\ \text { RothC } & \text { Rothamsted carbon model } \\ \text { model } & \\ \text { RPD } & \text { Ratio of performance to deviation } \\ R_{\text {adj }}{ }^{2} & \text { Adjusted coefficient of determination } \\ \text { SMU } & \text { Soil mapping units } \\ \text { SOC } & \text { Soil organic carbon } \\ \text { STU } & \text { Soil topological units }\end{array}$

J. Meersmans $(\bowtie) \cdot$ M. P. Martin · E. Lacarce $\cdot$ C. Jolivet $\cdot$

L. Boulonne $\cdot$ S. Lehmann $\cdot$ N. P. A. Saby $\cdot$ D. Arrouays

INRA Orléans, InfoSol Unit,

avenue de la pomme de pin 2163, CS 40001Ardon

45075 Orléans, cedex 2, France

e-mail: jeroen_meersmans@hotmail.com

S. De Baets

Earth and Life Institute (ELI), Georges Lemaître Centre for Earth and Climate Research (TECLIM), Université catholique de

Louvain,

Place Louis Pasteur 3, 1348 Louvain-la-Neuve, Belgium

A. Bispo

Agriculture and Forestry Department, ADEME, 49004, Angers, cedex 01, France

\begin{abstract}
Soil is a major carbon pool ruling the global $\mathrm{C}$ cycle Ane soil carbon is a source and a carbon ats la de and soil , to define efice 8 and , to define efficient land managennent practices. Thereof $250 \mathrm{~m}$. We study the inpact of land use, soil type, the impact of land use, soil type, en soil organic carbon. We P. Results also show that stock in France is about $3.7 \pm$ Pe the 列 
\end{abstract}




\section{Introduction}

Soil organic carbon (SOC) is a key element of soil quality as it is the main indicator of soil fertility. For example, it diminishes the risk of groundwater pollution because of its capacity to adsorb, immobilize and degrade contaminants such as pesticides and nitrates (e.g. Reeves 1997; OlveraVelona et al. 2008). Furthermore, different studies have shown that soil organic matter has a positive influence on soil aggregate stability and so should be considered as crucial in controlling soil erosion (e.g. Chenu et al. 2000; Chaney and Swift 1984) Moreover, given the active $\mathrm{C}$-exchange between soil and atmosphere, this reservoir is considered as a dynamic element in the global C-cycle, which underlines its potential to act as a driving factor on climate change feedbacks. Consequently, monitoring soil organic carbon is considered crucial in the framework of different international treaties such as the European Union Soil Thematic Strategy and the Kyoto Protocol. Hence, during the last decades, many studies were conducted to unravel the influence of different (agro-) management practices on the quantity and quality of carbon stored in the soil, such as land use change (e.g. Batlle-Aguilar et al. 2011), tillage or manure application (e.g. Morra et al. 2010; van Wesemael et al. 2010). In general, no-tillage or reduced tillage practices seems to result in higher SOC stocks as compared to conventional tillage (e.g. Stavi et al. 2011). Ludwig et al. (2011) concluded that the application of manure has the most beneficial effects on soil organic carbon in labile and intermediate pools, i.e. characterized by turnover times of $<10$ and 10-100 years.

Early estimates of total soil organic carbon stock were made at the global scale by combining worldwide soil databases with vegetation, land use or soil type maps and vary a lot, i.e. between 700 (Bolin 1970) and 3,000 Gt C (Bohn 1976). These values are higher than the total $\mathrm{C}$ amount stored in atmosphere. Given the rather complex interactions of soil carbon with many determining factors at smaller scales, recent studies investigated the spatial variability of SOC at the regional or national level. Therefore, these studies focus in detail on factors and processes explaining the heterogeneity of soil carbon, but they aim to combine this detailed information in order to predict and map carbon stocks and its evolution. Different methods are applied to catch the spatial distribution of SOC. For example, the traditional class matching approach predicts average carbon stocks by land use and/or soil type combination, whereby the carbon stocks are attributed to grid cells or polygons of the corresponding (overlay) map (Kern 1994; Arrouays et al. 2001; Batjes 2002). More enhanced geo-statistical interpolation techniques to map SOC also exist, i.e. ordinary kriging (Mishra et al. 2009) and scorpan kriging (Ungaro et al. 2010). Moreover, the Global Environment Facility Soil Organic Carbon (GEFSOC) modelling system links soil, climate, historical and current land use and land management data with existing process-based C-models (i.e. Century and Roth $\mathrm{C}$ ), via a geographical information system (GIS) interface, to make spatially explicit carbon stock and stock change predictions at the national and sub-national scale (Milne et al. 2007). Alternatively, a multidimensional empirical model can be constructed to predict soil organic carbon as a function of a set of environmental variables such as land use, soil type, climate and agricultural management. Such models can also be applied in a spatial context by combining its output with spatial data layers of the different input variables. For example, Martin et al. (2011) constructed a boosted regression tree model to study the spatial distribution of organic carbon in France, and Jones et al. (2005) developed a rule-based system provided by pedotransfer rules to map SOC in topsoil across Europe. Furthermore, Meersmans et al. (2011) developed a multiple linear regression model to map soil organic carbon in Belgium, in which the model terms (i.e. variables and their interaction terms) were added following a trial and error procedure in a way to maximize the adjusted coefficient of determination $\left(R_{\text {adj }}{ }^{2}\right)$ under the condition that all parameters are significant $(p<0.05)$.

So far the spatial distribution of soil organic carbon in France is estimated at rather coarse resolutions, i.e. following a $8 \times 8-\mathrm{km}$ grid in Arrouays et al. (2001) and a $12 \times$ $12 \mathrm{~km}$ grid in Martin et al. (2011), which is the consequence of a relatively low level of spatial detail of the input data used in these studies when mapping this dynamic soil property at the national scale. For example, Martin et al. 2011 used relative proportions of the different land uses aggregated at the departmental level when applying the boosted regression tree model in a spatial context. So, one can conclude that a refined soil organic carbon map for France could be made if more spatially detailed input data would be used, such as a land use map with higher resolution.

In this study, we aim to create a refined baseline map and total stock estimation of soil organic carbon for metropolitan France. Therefore, an existing empirical model, incorporating the effects of land use, soil type, climate and agricultural management calibrated at the national scale (Meersmans et al. 2012), is combined with detailed spatial data of the considered input variables (e.g. CORINE land cover map at resolution of $250 \mathrm{~m}$, Fig. 1). In comparison to earlier studies, Meersmans et al. (2012) presented a novel carbon model approach where the terms were not added following a trial and error process but following an automated model construction procedure, based on stepwise regression in combination with model selection criteria. 


\section{Material and methods}

\subsection{Study area}

France is situated in West Europe between approximately $5^{\circ} \mathrm{W}$ and $8^{\circ} \mathrm{E}$ and between $42^{\circ} \mathrm{N}$ and $51^{\circ} \mathrm{N}$. This country is rather diverse from a landscape, climatologic and pedologic point of view. The altitude ranges from sea level up to more than 4,000 $\mathrm{m}$ in the mountainous eastern part of the country (Alps). Climate is influenced by both latitudinal (north-south) and oceanic-continental (west-east) gradients and by relief-related effects. In general, temperature increases from the north, characterized by a temperate climate, to the south, characterized by a Mediterranean climate. Moreover, precipitation increases and temperature declines with increasing altitude. The Atlantic Ocean has an important influence on the climate because it diminishes intra-annual fluctuations. Nevertheless, the climate tends to become more continental further away from the ocean (Fig. 2) Despite the great heterogeneity in soil type, the 1/ 1,000,000 European soil map (King et al. 1995) allows us to distinguish some large areas dominated by specific soils: i.e. sandy soils in the south-west (Podsols in the Landes region), fertile loess soils (Luvisols) in the North, various shallow soils (Leptosols) developed from calcareous rocks (e.g. Champagne region, Jura and southern Alps mountains), and large areas of dystric Cambisols developed from the moderate weathering of different kinds of parent materials (Brittany, Massif Central mountains). The northern, western and central parts of the country are dominated by cropland, except in the Landes region, which is covered by coniferous forest and Normandy, characterized by vast areas of grassland. Moreover, forest and
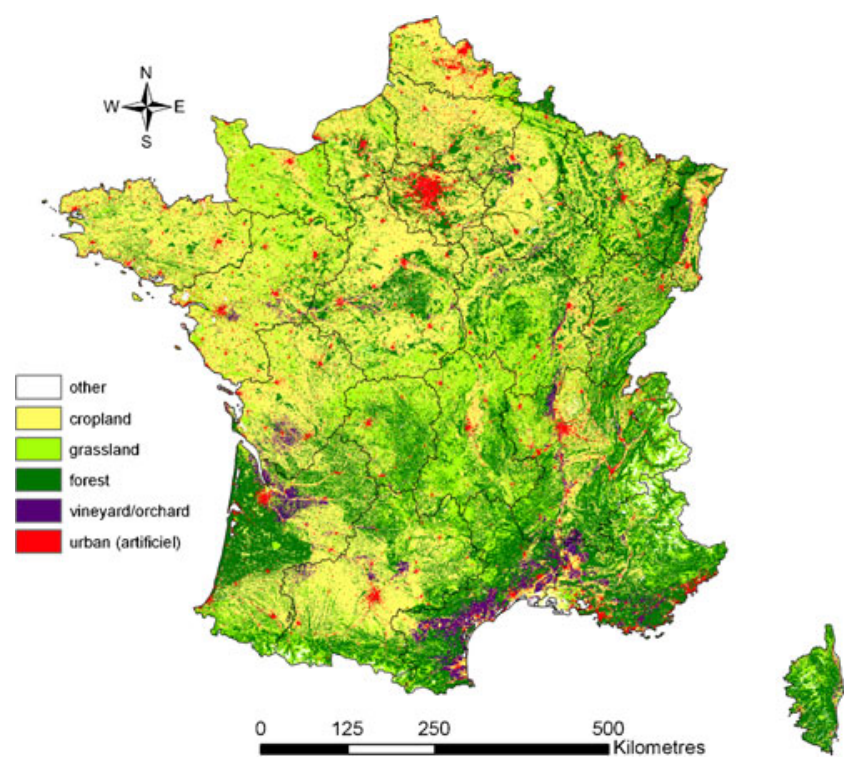

Fig. 1 General land use map of France obtained after reclassifying the CORINE land cover map 2006 (resolution $250 \mathrm{~m}$ ) permanent grasslands are the most common land uses in mountainous regions at altitudes of over $500 \mathrm{~m}$ above sea level. Vineyards and orchards can be found mainly in the south along the Mediterranean coast (Fig. 1).

\subsection{Climate data}

Average yearly temperature $\left({ }^{\circ} \mathrm{C}\right)$ and total annual precipitation $(\mathrm{mm})$ maps are obtained from a $0.125^{\circ} \times 0.125^{\circ}$ climatic grid distributed by Meteo-France, which has been obtained by interpolating observational data from the period 19932004 (Fig. 2).

\subsection{Manure data}

Manure application and animal excrement production statistics ( $\mathrm{t}$ ha year ${ }^{-1}$ ) at departmental level (ADEME, 2007) were combined with dry matter $\mathrm{C}$ concentration values, i.e. $37.7 \%$ for farm yard manure and $36.6 \%$ for slurry (Lashermes et al. 2009). Land use area statistics (AGRESTE, 2009) were then used to calculate average yearly $\mathrm{C}$ input related to farm yard manure and slurry production on agricultural soils as well as direct $\mathrm{C}$ input from animal excrements on grassland by department (Fig. 3).

\subsection{Land use map}

A general land use map for all of France with the following four land use classes was created: cropland, grassland, forest and vineyard/orchard. The land use map was made by reclassifying the most recent version of the CORINE 2006 land cover map, which has a resolution of $250 \mathrm{~m}$ and was derived from the SPOT 4 IRS P6 satellite image of the year 2006 (EEA 2007; Fig. 1).

\subsection{Soil type map}

The 1/1,000,000-scale Soil Geographical Database of France (i.e. based on European soil map) was used in this study (King et al. 1995). The database links the soil mapping units (SMU) to soil topological units (STU) with annotation of their proportion (in percent of area) within a SMU. Topsoil texture class, according to the CEC revised FAO classification triangle (CEC 1985), rock fragment content and maximal soil profile depth by STU were extracted or estimated using pedotransfer rules from this database. Moreover, clay and silt contents could be attributed to the corresponding STU by calculating median values by texture class using the entire French national soil inventory database (i.e. DoneSol 2.0, $N=17,484$ horizons; Meersmans et al. 2012). Finally, to map these soil properties, they were calculated by SMU after taking the weighted mean of their 

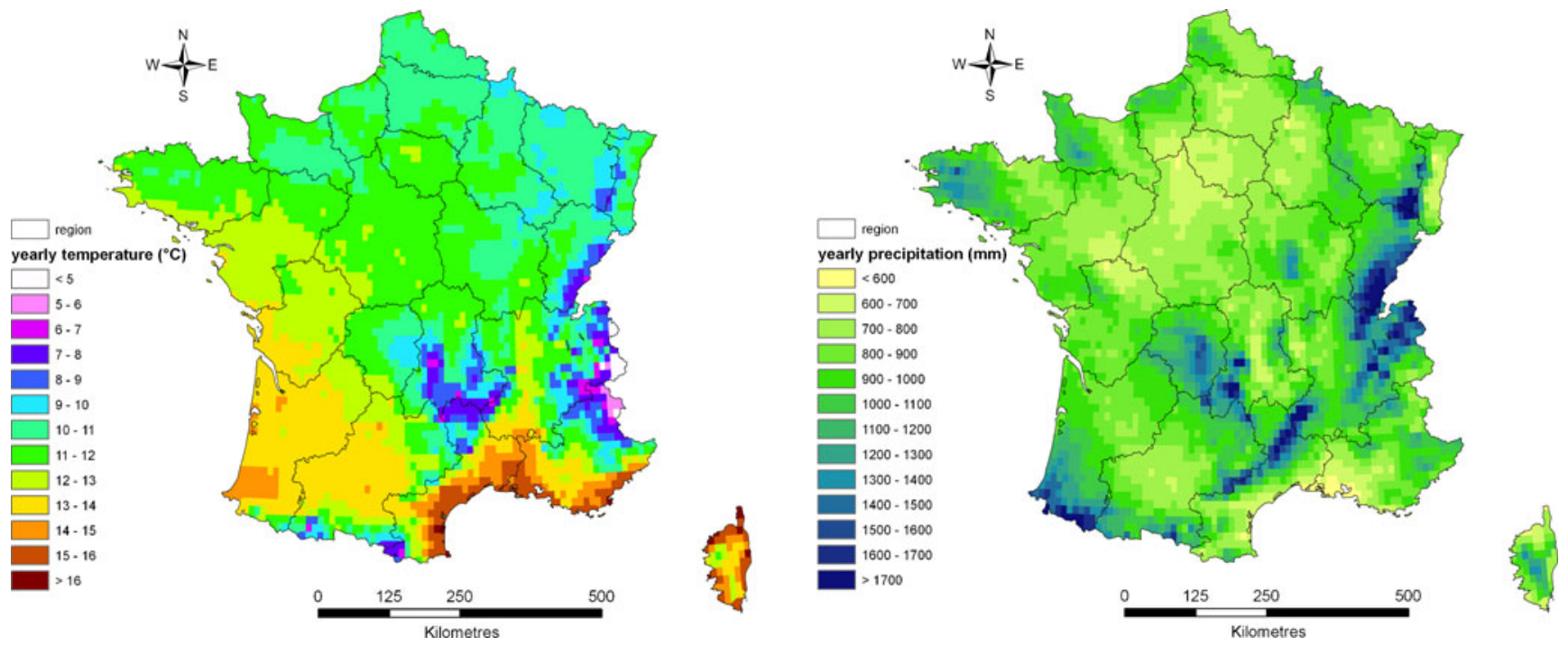

Fig. 2 Yearly average total precipitation $(\mathrm{mm})$ and temperature $\left({ }^{\circ} \mathrm{C}\right)$ map of France distributed by Meteo-France (1993-2004)

values by STU with the proportion of the STUs as weights (Fig. 4). Here we refer, according to the definition given by Poesen and Lavee (1994), with fine earth to soil particles with a diameter smaller than $2 \mathrm{~mm}$ and with rock fragments to particles with a diameter of $2 \mathrm{~mm}$ or larger.

\subsection{Soil organic carbon model}

In this study, SOC is mapped using an existing model (Meersmans et al. 2012) that has been calibrated based on the above mentioned climate and manure data in combination with soil data from a recent national soil survey (RMQS, Réseau de Mesures de la Qualité des Sols). This soil survey has been conducted by the French National
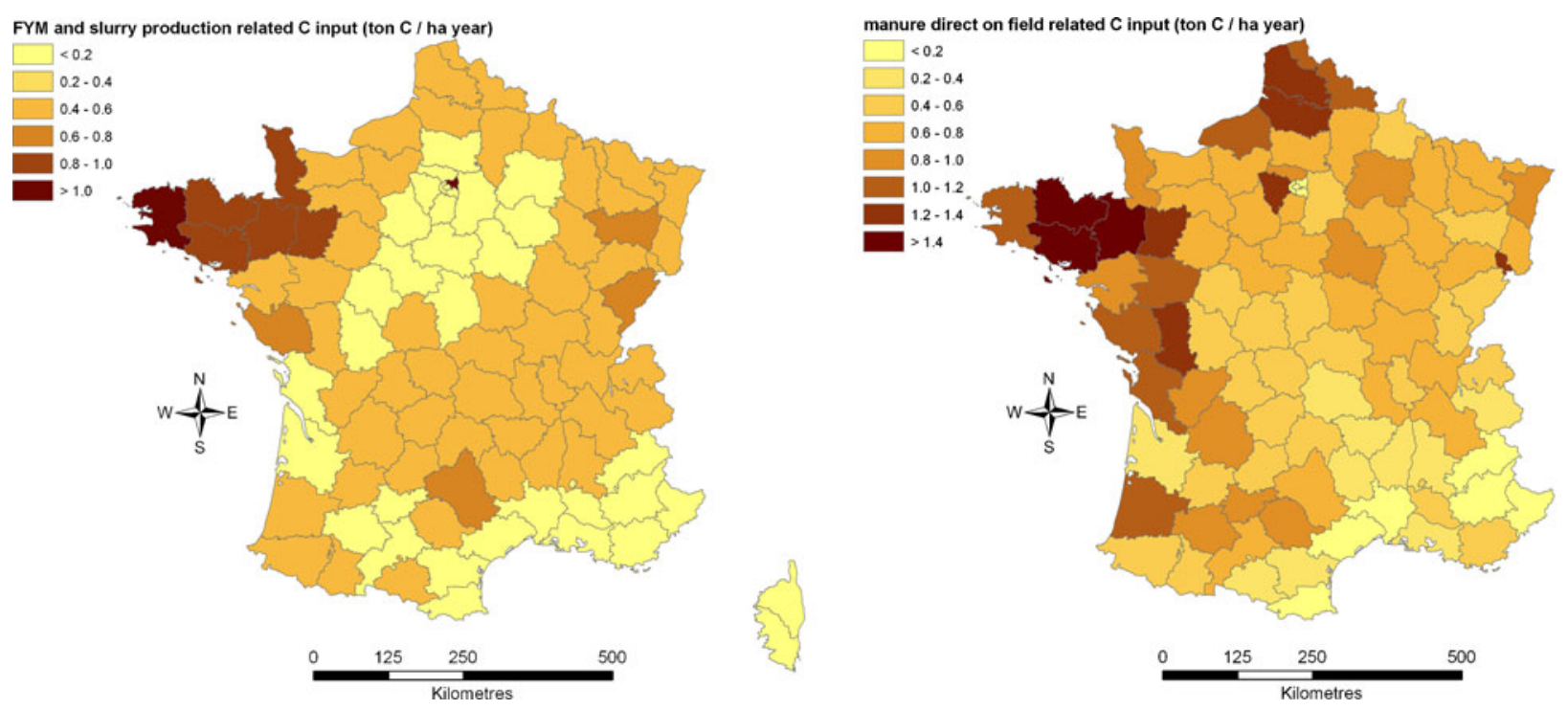

Institute for Agricultural Research (INRA), between 2000 and 2009, and contains 2,158 profiles continuously distributed over whole France following a $16 \times 16-\mathrm{km}$ grid (Arrouays et al. 2002).

Meersmans et al. (2012) constructed multiple linear regression models, predicting topsoil $(0.3 \mathrm{~m})$ organic carbon concentrations in fine earth as a function of land use, soil type, management and climate data using a stepwise regression method in combination with model selection criteria. First and second order interactions between the input variables were also taken into consideration. The following three different model selection criteria were considered: the Akaike information criterion (AIC), the corrected Akaike information criterion (AICc) and the Bayesian information

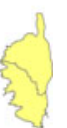

Fig. 3 Farm yard manure (FYM) and slurry production related C input and manure direct-on-field related C input by department map of France (ton $\mathrm{C} / \mathrm{ha} /$ year) 

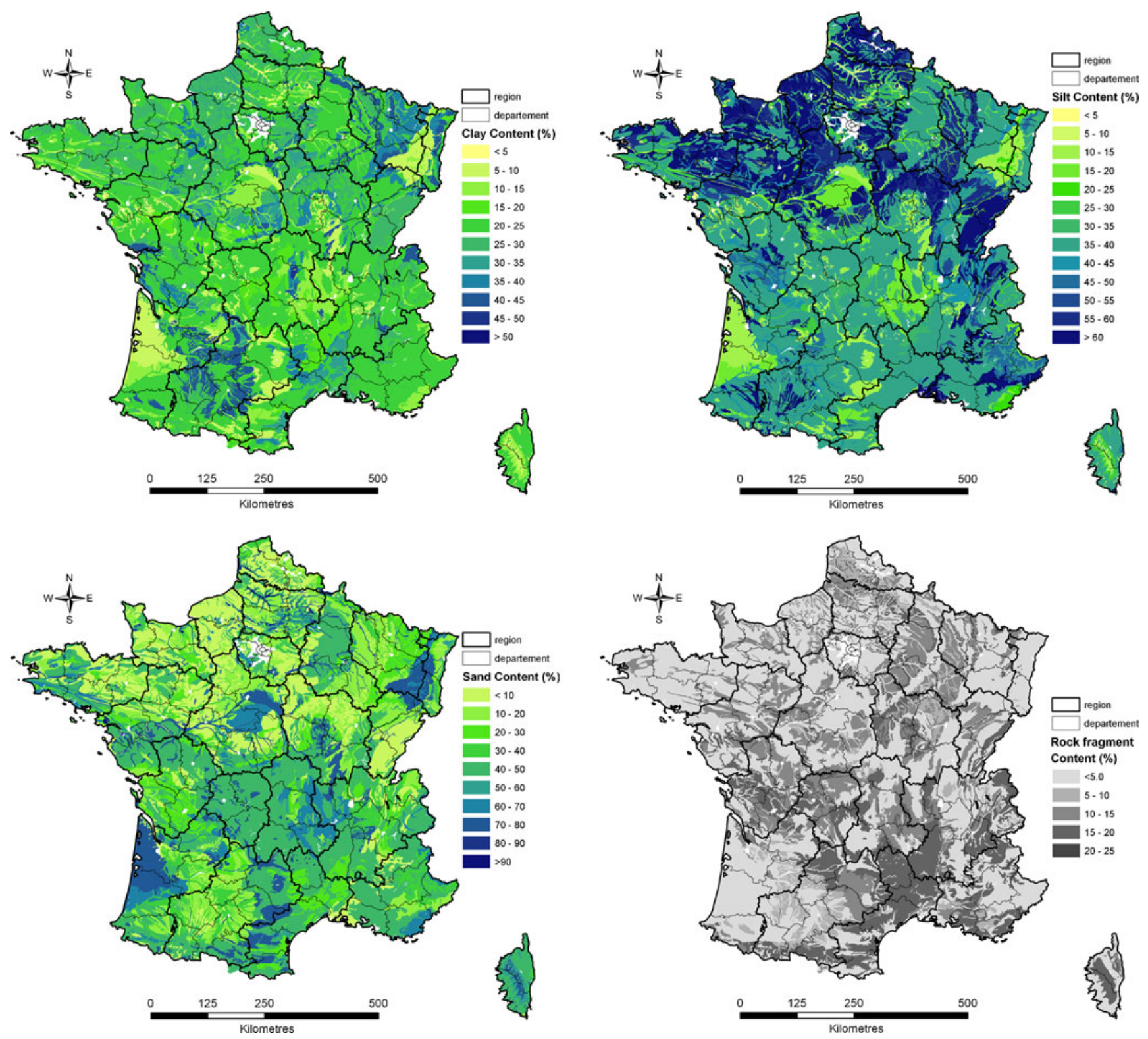

Fig. 4 Clay, silt, sand and rock fragment content (\%) map of France created based on 1,000,000-scale Soil Geographical Database of France (i.e. European soil map) and the French Soil inventory (Donesol 2.0)

criterion (BIC) (Akaike 1974; De Ridder et al. 2005). Using this automated model construction procedure, Meersmans et al. (2012) aimed to balance precision and accuracy in order to determine the terms that contribute to explaining the identified system. Model fit quality (adjusted coefficient of determination $\left(R_{\text {adj }}{ }^{2}\right)$ ) and validation measures (ratio of performance to deviation (RPD)) of the AIC and the AICc model were comparable, i.e. $R_{\mathrm{adj}}{ }^{2}=0.492$ and $\mathrm{RPD}=1.40$ for AIC and $R_{\mathrm{adj}}{ }^{2}=0.491$ and RPD $=1.39$ for AICc. The AIC model had 36 parameters, of which only 30 are significant $(p<0.05)$, whereas the AICc model had 30 parameters that are all significant. Furthermore, the model quality measures were remarkably lower for the BIC model (i.e. $R_{\mathrm{adj}}{ }^{2}=0.459$ and $\mathrm{RPD}=1.36$ ). Consequently, they focused on AIC and AICc model output and illustrated that under most climate, soil type, land use and agro-management settings, characterized by high sample density and output from both models, were rather comparable. Nevertheless, contrasting tendencies were identified under specific environments such as under croplands in relatively cold climates. More methodological information and detailed results concerning these models can be found in Meersmans et al. (2012).

The entire database used in Meersmans et al. (2012) is used in this study to perform an extra validation procedure. This dataset was sorted on soil organic carbon content and divided in 50 equal sub-datasets. Hence a repeated tenfold 
external cross-validation procedure (e.g. Hastie et al. 2001) could be applied on each sub-dataset in order to obtain a RMSE and to study the model predictive performance (RMSE) as a function of average estimated SOC concentration.

\subsection{Soil organic carbon mapping and stock estimations}

Here, the AIC and AICc model output of Meersmans et al. (2012) is combined with spatial data layers of land use, climate and soil type in order to map the spatial distribution of topsoil $(0.3 \mathrm{~m})$ organic carbon concentrations for metropolitan France. The resulting carbon map has a resolution of $250 \mathrm{~m}$ and covers approximately $92 \%$ of the total surface of metropolitan France. The total SOC stock is calculated after taking bulk density of the fine earth, soil depth and rock fragment content into account (Eq. 1). Soil bulk density of the fine earth is predicted based on modelled soil organic carbon values using the general PTF of Manrique and Jones (1991; Eq. 2). Country-wide total SOC storage is obtained by summing organic carbon stocks of all pixels multiplied by the pixel area (i.e. $62,500 \mathrm{~m}^{2}$ ).

$\mathrm{SOC}_{\text {stock }}=\frac{\mathrm{SOC}}{100} D(1-\mathrm{RF} / 100) \rho_{\mathrm{s}}$

where $\mathrm{SOC}_{\text {stock }}$ is soil organic carbon stock $\left(\mathrm{kg} \mathrm{m}^{-2}\right), \mathrm{SOC}$ is soil organic carbon concentration (\%), $D$ is depth (m), RF is volumetric rock fragment content $(\%)$ and $\rho_{\mathrm{s}}$ is bulk density of fine earth $\left(\mathrm{kg} \mathrm{m}^{3}\right)$.

$\rho_{\mathrm{s}}=(1.66-0.318 \sqrt{\mathrm{SOC}}) 1,000$

where SOC is soil organic carbon concentration (\%) and $\rho_{\mathrm{s}}$ is bulk density of fine earth $\left(\mathrm{kg} \mathrm{m}^{3}\right)$.

\subsection{Model error propagation estimation}

The model uncertainty on total carbon mass for France due to parameter uncertainty is predicted using the Monte Carlo (MC) error propagation technique. In each MC simulation, the parameter values are randomly perturbed following a normal probability distribution with a mean equal to the parameter value and a standard deviation equal to the estimated error of the parameter in order to calculate SOC concentration and in a second stage bulk density (Eq. 2) and SOC mass (Eq. 1) values. Due to computational restrictions (i.e. insufficient memory-RAM), it was not possible to apply this technique on all map pixels (i.e. $\sim 8 \times 10^{6}$ pixels). Hence, the error was calculated for a randomly selected $0.5 \%$ portion of the total pixel amount (i.e. $\sim 4 \times 10^{4}$ pixels) and by performing $500 \mathrm{MC}$ iterations. So, the summed soil organic carbon mass from the selected pixels was extrapolated in each MC simulation to a total countrywide SOC mass for entire France (i.e. after multiplying by 200). The standard deviation of the different calculated total carbon masses from all MC simulations was used as error on the total countrywide organic carbon mass prediction.

\subsection{Software}

Spatial analysis and mapping were carried out using the ArcGIS 9.3 software (ESRI, Redlands, California, USA). The R-software (version 2.9.0) was used for model validation and error propagation calculations.

\section{Results and discussion}

\subsection{Map and total stock}

Figure 5 shows the spatial distribution of soil organic carbon after combining the AICc model output with maps of different input variables. This map underlines the overall influence of climate on SOC. The strong correlation between climate and soil organic carbon has been as well identified at the continental scale by Rusco et al. (2001). They pointed to a general decline in SOC following a north west-south east increasing temperature gradient and a north-south decreasing precipitation gradient. The SOC map of France presented in this study clearly suggests that foremost precipitation dominates the spatial distribution of SOC with high concentrations of organic carbon in wet regions (i.e. mountainous areas; Figs. 2 and 5). This is in accordance with Martin et al. (2011) for France and with Meersmans et al. (2011) for Belgium, showing as well a stronger correlation with precipitation as compared to temperature.

On a smaller spatial scale, land use seems to be the most important factor explaining SOC variability within the landscape. Forested areas and grassland-dominated regions (e.g. Normandy in the north west (I, Figs. 1 and 5)) are characterized by much higher soil carbon contents compared to cropland-dominated areas (II, Figs. 1 and 5). Moreover, the very high SOC in regions characterized by high rainfall amounts are the result of a combined effect of climate and land use, because these regions are mainly covered by grasslands and forests.

High soil organic carbon contents under agricultural land in Brittany (III, Fig. 5) can be related to rather high precipitation amounts in this area but also to the very high farm yard manure and slurry production related $\mathrm{C}$ input (Figs. 2 and 3). Moreover, vineyard/orchard and croplands in the Mediterranean region are characterized by extremely low values, below $1 \%$ or even $0.5 \%$, SOC concentrations (IV, Fig. 5). The extremely low carbon contents (with values below $1 \%$ or even $0.5 \%$ ) in vineyard/orchard and croplands in the Mediterranean region need special attention (IV, Fig. 5). These soils are probably depleted due to intensive 

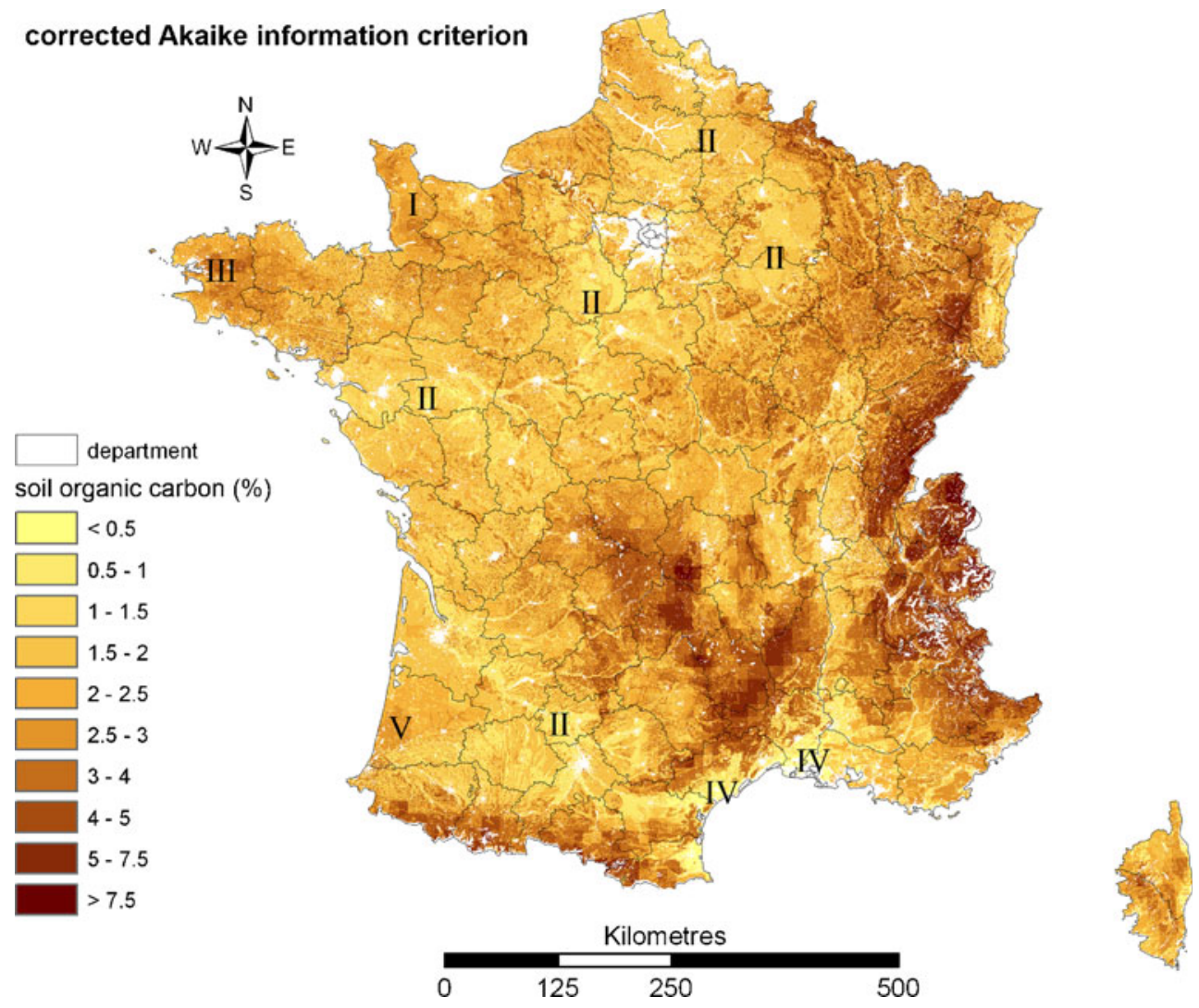

Fig. 5 Spatial distribution of SOC as predicted by the corrected Akaike information criterion (AICc) model. White areas correspond to environments where no soil organic carbon (SOC) prediction could be made (e.g. urban areas, intertidal zones, permanent snowfields, bedrock). This map shows that climate and land use dominate the spatial distribution of soil organic carbon in France. Most (mountainous) regions with high precipitation amounts are characterized by high

agricultural management practices applied over a long time period under favourable $\mathrm{C}$ mineralization conditions (i.e. relative low precipitation amounts and high temperatures). Because SOC is an important factor controlling aggregate stability (Chaney and Swift 1984; Saha et al. 2011), these soils risk losing aggregate stability and have serious fertility stress problems.

Many studies clearly illustrate that fine textured soils store much more soil organic carbon than coarse textured soils (e.g. Razafimbelo et al. 2008; Tan et al. 2004). Meersmans et al. (2012) confirm this relationship for France using the models applied in this paper. However, this effect is not well reflected in the spatial pattern of soil organic carbon at the national scale (Figs. 4 and 5). Nevertheless, one can find remarkably low carbon contents in some sandy soils situated in large river valleys. The poor spatial correlation between texture and soil organic carbon can be the consequence of the fact that in many cases land use depends on soil type. For example, one can expect very low carbon contents in the poor sandy soils of South West France (i.e. Podsols in Landes region), but as this particular organic carbon concentrations. Furthermore, low carbon concentrations are predicted in cropland-dominated regions (II) as well in the vineyard/orchards in the Mediterranean region (IV), while relative high carbon concentrations are detected in the vast grassland areas in Normandy (I) and coniferous forests in the South West (Landes, V). High soil organic carbon values in Brittany (III) can be related to rather high precipitation amounts and high manure application rates

region is of less interest for agricultural purposes it is almost entirely covered by forest (Fig. 1) and has relatively high carbon contents (V, Fig. 5). Or the other way round, regions dominated by fertile clay and/or silt-loam soils are of great interest for agriculture. As a consequence, they are most often characterized by vast areas of cropland and have rather low carbon contents (II, Fig. 5).

Figure 6 illustrates the spatial distribution of absolute differences between SOC obtained by the AIC model and by the AICc model. Differences in AIC and AICc spatial model outputs are limited and are most often below the absolute value of $1 \% \mathrm{C}$ (Fig. 6). This indicates that both methods give consistent results. Nevertheless, a few environments are characterized by rather big differences (up to more than $1.5 \% \mathrm{C}$ ). Lower values were obtained by applying the AIC instead of the AICc model under the following conditions: sandy, stony (i.e. a rock fragment of approximately $20 \%$ ) grassland soils under relatively wet conditions (i.e. more than $1,000 \mathrm{~mm}$; I, Fig. 6); sandy cropland soils under wet conditions (i.e. 1,500-2,000 mm; e.g. in valleys of Vosges Mountains, II, Fig. 6) and in silt-dominated 


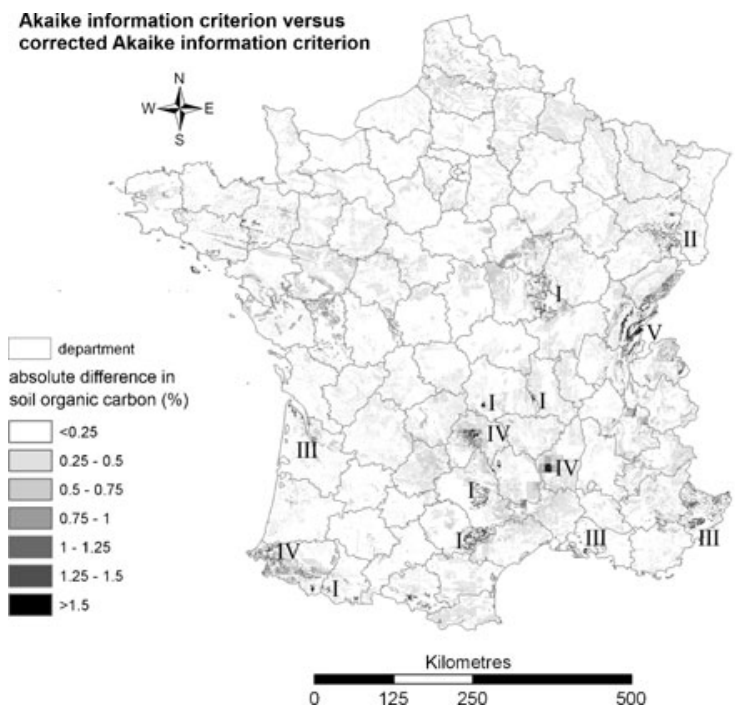

Fig. 6 Spatial distribution of difference in soil organic carbon (SOC) predictions made by the Akaike information criterion (AIC) model versus the corrected Akaike information criterion (AICc) model. In general, differences in AIC and AICc spatial model outputs are limited and are most often below the absolute value of $1 \%$. Lower values were obtained by applying the AIC instead of the AICc model under the following conditions: sandy, stony grassland soils under relatively wet conditions (I); sandy cropland soils under wet conditions (II); siltdominated grassland soils in relatively warm climates (III). Higher values are obtained by applying the AIC instead of the AICc model in many forested and grassland soils determined by very wet climate conditions in mountainous regions (IV) or stony silt-dominated forest soils in the Jura region $(\mathrm{V})$

grassland soils in relatively warm climates (i.e. more than $13^{\circ} \mathrm{C}$; III, Fig. 6). Higher values are obtained by applying the AIC instead of the AICc model in many forested and grassland soils determined by very wet climate conditions (i. e. more than 1,500 mm) in mountainous regions (IV, Fig. 6) or stony silt-dominated forest soils in the Jura region (V, Fig. 6). This is in accordance with the finding of Meersmans et al. (2012), who illustrate that AIC and AICc model outputs diverge towards higher rock fragment contents (i.e. above $25 \%$ ) as well as for wet climates under cropland or coarse textured grassland soils. Most of these environments are characterized by a limited number of samples and rather high uncertainties. But, as their spatial occurrence is restricted, this does not affect the present carbon map and total stock predictions at the national scale much.

By taking soil bulk density, soil depth and rock fragment content into account, total soil organic carbon stock for entire France was calculated at $3.75 \pm 1.27$ and $3.72 \pm 1.26 \mathrm{Pg} \mathrm{C}$ using the AIC and AICc models, respectively. This corresponds to an overall average carbon stock of 7.40 (AIC) and $7.36 \mathrm{~kg} \mathrm{C} \mathrm{m}^{-2}$ (Table 1), indicating that the influence of the model choice is limited on total countrywide SOC mass predictions. The total organic carbon stock in the top $0.3 \mathrm{~m}$ for France obtained in the present study is higher than the values published by Arrouays et al. (2001) and Martin et al. (2011; i.e. 3.10 and $3.26 \pm 0.84 \mathrm{Pg}$, respectively), but as the values illustrate these differences are not significant. It is rather difficult to identify the main causes of these differences in countywide total carbon stock estimates. One reason might be the fact that different methods have been used to predict and map SOC. Arrouays et al. (2001) attributed mean carbon stock values to land use-soil type combination and Martin et al. (2011) constructed a boosted regression tree model to predict soil organic carbon based on land use, soil type, climate and net primary productivity. Another possible factor is the difference in mapping scale. In this study, SOC stocks are mapped at a resolution of $250 \mathrm{~m}$, whereas Arrouays et al. (2001) and Martin et al. (2011) mapped soil carbon in $8 \times 8$ and $12 \times 12 \mathrm{~km}$ grids, respectively. Moreover, different land use maps were used to apply the model in a spatial context. Finally, Martin et al. (2011) first converted soil organic carbon concentrations (in fine earth) into stocks by site and then calibrated the boosted regression tree model based on these SOC stocks, whereas we calibrated the model based on SOC concentrations and later converted the predicted concentrations into SOC stocks.

Land use specific average SOC stocks are also comparable between both methods. Average SOC stock under forest (i.e. 9.48 (AIC) $-9.41 \mathrm{~kg} \mathrm{C} \mathrm{m}^{-2}$ (AICc)) is somewhat higher than under grassland (i.e. 8.55 (AIC)-8.58 $\mathrm{kg} \mathrm{C} \mathrm{m}^{-2}$ (AICc)), whereas average SOC stock under vineyard and orchard (i.e. 3.14 (AIC) $-3.27 \mathrm{~kg} \mathrm{C} \mathrm{m}^{-2}$ (AICc)) is lower than under cropland (i.e. 5.64 (AIC) $-5.57 \mathrm{~kg} \mathrm{C} \mathrm{m}^{-2}$ (AICc); Table 1). These values are also higher than the ones reported by Martin et al. (2011), i.e. $7.57 \mathrm{~kg} \mathrm{C} \mathrm{m}^{-2}$ for forest, $7.00 \mathrm{~kg} \mathrm{C} \mathrm{m}^{-2}$ for
Table 1 Overall and land use specific total soil organic carbon (SOC) mass (Pg C) and average SOC stock $\left(\mathrm{kg} \mathrm{Cm}^{-2}\right)$

AIC Akaike information criterion, $A I C c$ corrected Akaike information criterion

\begin{tabular}{|c|c|c|c|c|c|}
\hline \multirow[t]{2}{*}{ Land use } & \multirow[t]{2}{*}{ Area $\left(\mathrm{km}^{2}\right)$} & \multicolumn{2}{|c|}{ Total SOC mass (Pg C) } & \multicolumn{2}{|c|}{ Average SOC stock $\left(\mathrm{kg} \mathrm{C} \mathrm{m}^{-2}\right)$} \\
\hline & & AIC & $\mathrm{AICc}$ & AIC & $\mathrm{AICc}$ \\
\hline Cropland & 226276 & 1.277 & 1.261 & 5.64 & 5.57 \\
\hline Grassland & 106537 & 0.910 & 0.914 & 8.55 & 8.58 \\
\hline Forest & 160053 & 1.517 & 1.506 & 9.48 & 9.41 \\
\hline Vineyard/orchard & 13278 & 0.042 & 0.043 & 3.14 & 3.27 \\
\hline All & 506144 & 3.746 & 3.725 & 7.40 & 7.36 \\
\hline
\end{tabular}


grassland, $3.20 \mathrm{~kg} \mathrm{C} \mathrm{m}^{-2}$ for vineyard/orchard and $4.74 \mathrm{~kg} \mathrm{C}$ $\mathrm{m}^{-2}$ for cropland. Nevertheless, we can state that the general spatial distribution pattern of these studies can be compared rather well. All studies identified high SOC values in Mountainous regions (characterized by wet climates), in Normandy and in Brittany and low SOC values in cropland-dominated regions and for the Mediterranean area.

\subsection{Error, validation and evaluation}

The median relative model error (i.e. model error divided by predicted value) on the total national SOC stock was 33.9\% as calculated using the MC method for both models. This is rather low as compared to the model error values for individual organic carbon predictions obtained by Meersmans et al. (2012), i.e. a median relative model error of $46.6 \%$ for the AICc model and $59.7 \%$ for the AIC model. Moreover, the average RMSE values for the 50 sub-datasets ranged between $1 / 2$ and $1 / 3$ of their estimated SOC value (Fig. 7), except for extremely low carbon values (below 1\%) for which the relative RMSE value is considerably higher. This high relative RMSE for low values is most pronounced for the AIC model, which occasionally predicts irrational

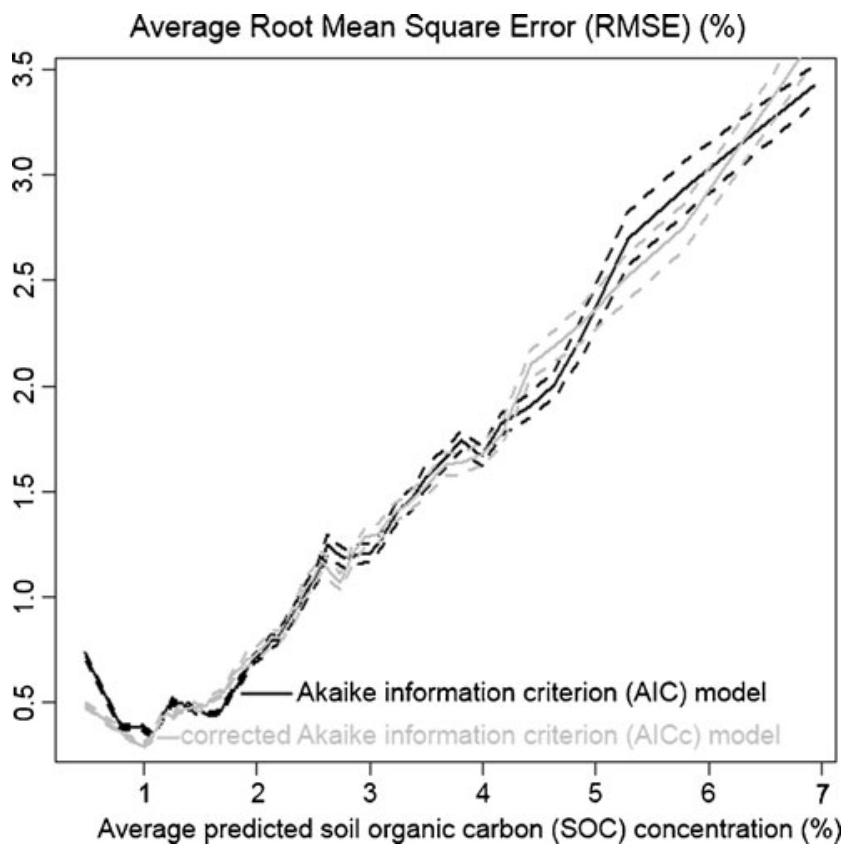

Fig. 7 Average Root Mean Square Error (RMSE; \%) versus average predicted soil organic carbon (SOC) concentration (\%) of 50 subdatasets. Dashed lines present $95 \%$ confidence interval limits on the average predicted RMSE error obtained by external cross validation. Black indicates Akaike information criterion (AIC) model; grey indicates corrected Akaike information criterion (AICc) model. Average RMSE values for the 50 sub-datasets ranged between $1 / 2$ and $1 / 3$ of their estimated SOC value, except for extremely low carbon values (below 1\%) for which the relative RMSE value is considerably higher. This high relative RMSE for low values is most pronounced for the AIC model negative organic carbon concentrations (i.e. for stony sandy grassland soils occupying $0.1 \%$ of the total study area). We therefore recommend using the less complex AICc model in order to map soil organic carbon. In the stock predications, we set these negative values to $0 \%$ to avoid a systematic under prediction of the total SOC mass.

Despite the rather high RMSE and relative model error values, the model choice has little effect on the spatial prediction of soil organic carbon and total stock calculations (Fig. 7 and Table 1). This indicates that the stepwise multiple linear regression model approach in combination with model selection criteria is a powerful tool for SOC mapping at the regional or national scale and the risk of systematic over/underprediction of total soil carbon storage by using different model selection criteria is limited. In the context of current-day climate change and soil fertility problems, these maps appear to be a reliable tool for developing appropriate soil management practices.

Nevertheless, one should notice the inconsistency between the SOC mapping resolution of $250 \mathrm{~m}$ and manure application data at departmental level. Probably a more clear relation between soil carbon and manure could be identified and more detailed and reliable carbon maps could be obtained if this variable was available at a finer spatial scale. This underlines the importance of collecting manure data at the field scale, e.g. detailed agro survey completed by the farmers at the sample sites. Furthermore, one can see that the climate grid is reflected in the SOC map. This indicates that if this type of data was available at a finer grid, this would probably result in more accurate and detailed spatial predictions. Moreover, Meersmans et al. (2008) integrated soil drainage (i.e. maximal and minimal depth of the ground water) in their model and showed that this variable is one of the main factors explaining soil carbon variability at the regional scale. This variable was not available for France. We believe that the overall model uncertainty of the present study would be considerably lower if we would have been able to integrate soil drainage (e.g. depth of ground water) in the model. Other potentially interesting variables to increase the predictive power of the model can be topography (i.e. slope, curvature; e.g. Van Oost et al. 2007), net primary production (Martin et al. 2011), land use history (i.e. years since land use change or abandonment; e.g. Stevens and van Wesemael 2008), total soil depth and tillage depth (e.g. Meersmans et al. 2009)

\section{Conclusions}

Climate dominates the general spatial pattern of SOC in metropolitan France. There are noticeably high organic carbon concentrations in mountainous areas characterized by high precipitation amounts. Land use seems also to be a very 
important factor influencing SOC heterogeneity. Forested areas and grassland-dominated areas are characterized by much higher carbon contents compared to cropland-dominated regions. Furthermore, croplands and vineyards/orchards in the Mediterranean region are characterized by extremely low SOC concentrations, with values dropping even below $0.5 \%$. High soil organic carbon contents in the West can be related to high manure application rates. Despite the fact that the models used in this study identified an important effect of texture on soil carbon (Meersmans et al. 2012), it was not obvious to detect this relationship on the map. The differences between the soil organic carbon maps created by applying the AIC and AICc models are rather small, indicating that the choice of the model does not have a large effect on the spatial prediction and total stock calculation. The total SOC stock for France is calculated at $3.75 \pm 1.27$ (AIC model) or $3.72 \pm 1.26 \mathrm{Pg}$ C (AICc model). Nevertheless, the AIC model has a surprisingly high relative RMSE for extremely low soil carbon concentrations (i.e. less than $1 \%$ ) and predicts in very few cases unrealistic negative soil carbon values ( $0.1 \%$ of the total study area), which is probably the consequence of overfitting. We therefore recommend using the less complex AICc model in order to map SOC for France. More spatially detailed information regarding manure and climate would probably result in more accurate carbon maps. The refined soil organic carbon map presented in this study appears to be useful as a policy tool in conducting sustainable soil management at the national scale.

Acknowledgements The RMQS was financed by the "Groupement d'Intérêt Scientifique Sol". Jeroen Meersmans post-doctoral position was funded by the French Environment and Energy Management Agency (ADEME). We thank all the people involved in sampling and sample preparation and analysis.

\section{References}

ADEME (French Environment and Energy Management Agency) (2007) Bilan des flux de contaminants entrant sur les sols agricoles de France métropolitaine - final report: Bilan qualitatif de la contamination par les éléments tracés métalliques et les composés tracés organiques et application quantitative pour les éléments tracés métalliques

AGRESTE (Ministère de l'Alimentation, de l'Agriculture et de la Pêche) (2009) Chiffres et Données-Série Agriculture, 208, L'utilisation du territoire en 2008-Teruti-Lucas

Akaike H (1974) New look at statistical-model identification. IEEE Trans Autom Control AC 19:716-723. doi:10.1109/TAC.1974.1100705

Arrouays D, Deslais W, Badeau V (2001) The carbon content of topsoil and its geographical distribution in France. Soil Use Manag 17:711. doi:10.1111/j.1475-2743.2001.tb00002.x

Arrouays D, Jolivet C, Boulonne L, Bodineau G, Saby N, Grolleau E (2002) A new initiative in France: a multi-institutional soil quality monitoring network. Comptes rendus de l'Academie d'Agriculture de France 88:93-105

Batjes NH (2002) Carbon and nitrogen stocks in the soils of Central and Eastern Europe. Soil Use Manag 18:324-329. doi:10.1079/ SUM2002138
Batlle-Aguilar J, Brovelli A, Porporato A, Barry DA (2011) Modelling soil carbon and nitrogen cycles during land use change. A review. Agron Sustain Dev 31:251-274. doi:10.1051/agro/2010007

Bohn HL (1976) Estimates of organic carbon in world soils. Soil Sci Soc Am J 40:468-470

Bolin B (1970) Carbon Cycle. Sci Am 223:124-132

CEC (1985) Soil Map of the European Communities at 1:1.000.000. CEC DG VI, Brussels-Luxembourg

Chaney K, Swift RS (1984) The influence of organic-matter on aggregate stability in some British soils. J Soil Sci 35:223-230. doi:10.1111/j.1365-2389.1984.tb00278.x

Chenu C, Le Bissonnais Y, Arrouays D (2000) Organic matter influence on clay wettability and soil aggregate stability. Soil Sci Soc Am J 64:1479-1486

De Ridder F, Pintelon R, Schoukens J, Gillikin DP (2005) Modified AIC and MDL model selection criteria for short data records. IEEE Trans Instrum Meas 54:144-150. doi:10.1109/TIM.2004.838132

EEA (2007) CLC2006 technical guidelines, Technical report No. 17/ 2007. European Environment Agency, Copenhagen

Hastie T, Tibshirani R, Friedman J (2001) The elements of statistical learning, data mining, inference, and prediction, Springer Series in statistics, 2nd edn. Springer, New York

Jones RJA, Hiederer R, Rusco E, Montanarella L (2005) Estimating organic carbon in the soils of Europe for policy support. Eur J Soil Sci 56:655-671. doi:10.1111/j.1365-2389.2005.00728.x

Kern JS (1994) Spatial patterns of soil organic carbon in the contiguous United States. Soil Sci Soc Am J 58:439-455

King D, Burill A, Daroussin J, Le Bas C, Tavernier R, Van Ranst E (1995) The EU soil geographical database. In: King D, Jones RJA, Thomasson AJ (eds) European Land Information Systems for Agro-environmental Monitoring, EUR 16232 EN. Office for Official Publications of the European Communities, Luxembourg

Lashermes G, Nicolardot B, Parnaudeau V, Thuries L, Chaussod R, Guillotin ML, Lineres M, Mary B, Metzger L, Morvan T, Tricaud A, Villette C, Houot S (2009) Indicator of potential residual carbon in soils after exogenous organic matter application. Eur J Soil Sci 60:297-310. doi:10.1111/j.1365-2389.2008.01110.x

Ludwig B, Geisseler D, Michel K, Joergensen RG, Schulz E, Merbach I, Raupp J, Rauber R, Hu K, Niu L, Liu X (2011) Effects of fertilization and soil management on crop yields and carbon stabilization in soils. A review. Agron Sustain Dev 31:361-372. doi: 10.1051/agro/2010030

Manrique LA, Jones CA (1991) Bulk density of soils in relation to soil physical and chemical properties. Soil Sci Soc Am J 55:476-481

Martin MP, Wattenbach M, Smith P, Meersmans J, Jolivet C, Boulonne L, Arrouays D (2011) Spatial distribution of soil organic carbon stocks in France. Biogeosciences 8:1053-1065. doi:10.5194/bg-8-10532011

Meersmans J, De Ridder F, Canters F, De Baets S, Van Molle M (2008) A multiple regression approach to assess the spatial distribution of Soil Organic Carbon (SOC) at the regional scale (Flanders, Belgium). Geoderma 143:1-13. doi:10.1016/j. geoderma.2007.08.025

Meersmans J, Van Wesemael B, De Ridder F, Dotti MF, De Baets S, Van Molle M (2009) Changes in organic carbon distribution with depth in agricultural soils in northern Belgium, 1960-2006. Glob Change Biol 15:2739-2750. doi:10.1111/j.1365-2486.2009.01855.x

Meersmans J, van Wesemael B, Goidts E, van Molle M, De Baets S, De Ridder F (2011) Spatial analysis of soil organic carbon evolution in Belgian croplands and grasslands, 1960-2006. Glob Change Biol 17:466-479. doi:10.1111/j.1365-2486.2010.02183.x

Meersmans J, Martin MP, De Ridder F, Lacarce E, Wetterlind J, De Baets S, Le Bas C, Louis BP, Orton TG, Bispo A, Arrouays, D (2012) A novel soil organic C model using climate, soil type and management data at the national scale (France). Agron Sustain Dev. doi:10.1007/s13593-012-0085-x 
Milne E, Al Adamat R, Batjes NH, Bernoux M, Bhattacharyya T, Cerri CC, Cerri CEP, Coleman K, Easter M, Falloon P, Feller C, Gicheru P, Kamoni P, Killian K, Pal DK, Paustian K, Powlson DS, Rawajfih Z, Sessay M, Williams S, Wokabi S (2007) National and sub-national assessments of soil organic carbon stocks and changes: The GEFSOC modelling system. Agric Ecosyst Environ 122:3-12. doi:10.1016/j.agee.2007.01.002

Mishra U, Lal R, Slater B, Calhoun F, Liu D, Van Meirvenne M (2009) Predicting soil organic carbon stock using profile depth distribution functions and ordinary kriging. Soil Sci Soc Am J 73:614621. doi:10.2136/sssaj2007.0410

Morra L, Pagano L, Iovieno P, Baldanton A, Alfani A (2010) Soil and vegetable crop response to addition of different levels of municipal waste compost under Mediterranean greenhouse condition. Agron Sustain Dev 30:701-709. doi:10.1051/agro/2009046

Olvera-Velona A, Benoit P, Barriuso E, Ortiz-Hernandez L (2008) Sorption and desorption of organophosphate pesticides, parathion and cadusafos, on tropical agricultural soils. Agron Sustain Dev 28:231-238. doi:10.1051/agro:2008009

Poesen J, Lavee H (1994) Rock fragments in top soils - significance and processes. Catena 23: 1-28. doi:10.1016/0341-8162(94) 90050-7

Razafimbelo TM, Albrecht A, Oliver R, Chevallier T, Chapuis-Lardy L, Feller C (2008) Aggregate associated-C and physical protection in a tropical clayey soil under Malagasy conventional and notillage systems. Soil Tillage Res 98:140-149. doi:10.1016/j. still.2007.10.012

Reeves DW (1997) The role of soil organic matter in maintaining soil quality in continuous cropping systems. Soil Tillage Res 43:131167. doi:10.1016/S0167-1987(97)00038-X
Rusco E, Jones R, Bidoglio G (2001) Organic matter in the soils of Europe: present status and future trends, European Soil Bureau, Soil and Waste Unit, Institute for Environment and Sustainability. JRC Ispra, Institute, Joint Research Centre European Commission, Italy

Saha D, Kukal SS, Sharma S (2011) Landuse impacts on SOC fractions and aggregate stability in typic ustochrepts of Northwest India. Plant Soil 339:457-470. doi:10.1007/s11104-010-0602-0

Stavi I, Lal R, Owens LB (2011) On-farm effects of no-till versus occasional tillage on soil quality and crop yields in eastern Ohio. Agron Sustain Dev 31:475-482. doi:10.1007/s13593-011-0006-4

Stevens A, van Wesemael B (2008) Soil organic carbon stock in the Belgian Ardennes as affected by afforestation and deforestation from 1868 to 2005. For Ecol Manag 256:1527-1539. doi:10.1016/ j.foreco.2008.06.041

Tan ZX, Lal R, Smeck NE, Calhoun FG (2004) Relationships between surface soil organic carbon pool and site variables. Geoderma 121:187-195. doi:10.1016/j.geoderma.2003.11.003

Ungaro F, Staffilani F, Tarocco P (2010) Assessing and mapping topsoil organic carbon stocks at regional scale: a scorpan kriging approach conditional on soil map delineations and land use. Land Degrad Dev 21:565-581. doi:10.1002/ldr.998

Van Oost K, Quine TA, Govers G, De Gryze S, Six J, Harden JW, Ritchie JC, McCarty GW, Heckrath G, Kosmas C, Giraldez JV, da Silva JRM, Merckx R (2007) The impact of agricultural soil erosion on the global carbon cycle. Science 318:626-629. doi:10.1126/ science. 1145724

van Wesemael B, Paustian K, Meersmans J, Goidts E, Barancikova G, Easter M (2010) Agricultural management explains historic changes in regional soil C stocks. Proc Natl Acad Sci USA 107:14926-14930. doi:10.1073/pnas.1002592107 